\title{
QUEEN'S
UNIVERSITY
BELFAST
}

\section{Tooth replacement for partially dentate elders: a willingness-to-pay analysis}

McKenna, G., Tada, S., Woods, N., Hayes, M., DaMata, C., \& Allen, P. F. (2016). Tooth replacement for partially dentate elders: a willingness-to-pay analysis. Journal of Dentistry. https://doi.org/10.1016/j.jdent.2016.07.006

\author{
Published in: \\ Journal of Dentistry
}

\section{Document Version:}

Peer reviewed version

\section{Queen's University Belfast - Research Portal:}

Link to publication record in Queen's University Belfast Research Portal

\section{Publisher rights}

(c) 2016 Elsevier B. V. This manuscript version is made available under the CC-BY-NC-ND 4.0 license

http://creativecommons.org/licenses/by-nc-nd/4.0/,which permits distribution and reproduction for non-commercial purposes, provided the author and source are cited.

\section{General rights}

Copyright for the publications made accessible via the Queen's University Belfast Research Portal is retained by the author(s) and / or other copyright owners and it is a condition of accessing these publications that users recognise and abide by the legal requirements associated with these rights.

Take down policy

The Research Portal is Queen's institutional repository that provides access to Queen's research output. Every effort has been made to ensure that content in the Research Portal does not infringe any person's rights, or applicable UK laws. If you discover content in the Research Portal that you believe breaches copyright or violates any law, please contact openaccess@qub.ac.uk. 


\section{Accepted Manuscript}

Title: Tooth replacement for partially dentate elders: a willingness-to-pay analysis

Author: G. McKenna Senior Lecturer/Consultant S. Tada Researcher N. Woods Centre Director M. Hayes Lecturer in Restorative Dentistry C. DaMata Lecturer in Restorative Dentistry Cork P.F. Allen Professor of Prosthodontics and Oral Rehabilitation

PII: S0300-5712(16)30131-2

DOI: http://dx.doi.org/doi:10.1016/j.jdent.2016.07.006

Reference: JJOD 2642

To appear in: Journal of Dentistry

Received date: 18-12-2015

Revised date: $\quad$ 8-7-2016

Accepted date: $11-7-2016$

Please cite this article as: McKenna G, Tada S, Woods N, Hayes M, DaMata C, Allen P.F.Tooth replacement for partially dentate elders: a willingness-to-pay analysis.Journal of Dentistry http://dx.doi.org/10.1016/j.jdent.2016.07.006

This is a PDF file of an unedited manuscript that has been accepted for publication. As a service to our customers we are providing this early version of the manuscript. The manuscript will undergo copyediting, typesetting, and review of the resulting proof before it is published in its final form. Please note that during the production process errors may be discovered which could affect the content, and all legal disclaimers that apply to the journal pertain. 


\section{Tooth replacement for partially dentate elders: a willingness-to-pay analysis}

Short title: Older patients WTP for tooth replacement

McKenna G, Senior Lecturer / Consultant, Centre for Public Health, Queens University Belfast

Tada S, Researcher, Department of Prosthodontics, Gerodontology and Oral Rehabilitation, Osaka University

Woods N, Centre Director, Centre for Policy Studies, University College Cork

Hayes $M$, Lecturer in Restorative Dentistry, Cork University Dental School and Hospital, University College Cork

DaMata C, Lecturer in Restorative Dentistry Cork, University Dental School and Hospital, University College Cork

Allen PF, Professor of Prosthodontics and Oral Rehabilitation, Cork University Dental School and Hospital, University College Cork

Corresponding Author: $\operatorname{Dr}$ G McKenna, Senior Lecturer / Consultant, Centre for Public Health, Queens University Belfast, Institute of Clinical Sciences Block B, Grosvenor Road, Belfast, BT12 6BJ. Tel.: (+44) 02890 976311; Fax: (+44) 02890235900

Email: g.mckenna@qub.ac.uk 


\section{Abstract}

Objectives: The primary aim of this study was to investigate partially dentate elders' willingness-to-pay (WTP) for two different tooth replacement strategies: Removable Partial Dentures (RPDs) and, functionally orientated treatment according to the principles of the Shortened Dental Arch (SDA). The secondary aim was to measure the same patient groups' WTP for dental implant treatment.

Methods: 55 patients who had completed a previous RCT comparing two tooth replacement strategies (RPDs $(n=27)$ and SDA $(n=28))$ were recruited (Trial Registration no. ISRCTN26302774). Patients were asked to indicate their WTP for treatment to replace missing teeth in a number of hypothetical scenarios using the payment card method of contingency evaluation coupled to different costs. Data were collected on patients' social class, income levels and other social circumstances. A Mann-Whitney U Test was used to compare differences in WTP between the two treatment groups. To investigate predictive factors for WTP, multiple linear regression analyses were conducted.

Results: The median age for the patient sample was 72.0 years (IQR: 71-75 years). Patients who had been provided with RPDs indicated that their WTP for this treatment strategy was significantly higher (€550; IQR: 500-650) than those patients who had received SDA treatment (€500; IQR: 450-550) ( $p=0.003)$. However patients provided with RPDs indicated that their WTP for SDA treatment (€650; IQR: 600-650) was also significantly higher than those patients who had actually received functionally orientated treatment ( $€ 550$; IQR: 500$600)(p<0.001)$. The results indicated that both current income levels and previous treatment allocation were significantly correlated to WTP for both the RPD and the SDA groups. Patients in both treatment groups exhibited little WTP for dental implant treatment with a median value recorded which was half the market value for this treatment $(€ 1000$; IQR: 500-1000).

Conclusions: Amongst this patient cohort previous treatment experience had a strong influence on WTP as did current income levels. Both treatment groups indicated a very 
strong WTP for simpler, functionally orientated care using adhesive fixed prostheses (SDA) over conventional RPDs.

Clinical significance: Partially dentate older patients expressed a strong preference for functionally orientated tooth replacement as an alternative to conventional RPDs.

Keywords: Geriatric dentistry, Economic evaluation, Fixed and removable prosthodontics, Clinical studies, Dental implants

\section{Introduction}

Management of oral care in older patients has significant health relevance with oral disease affecting an estimated 3.9 billion people worldwide ${ }^{1}$. The costs of care delivery and maintenance continue to increase dramatically which in turn has negative impacts on access to oral healthcare for older patients ${ }^{2}$. Across many developed countries, increasing levels of natural tooth retention has given rise to a largely partially dentate older population. The effects of oral disease can be difficult and costly to manage in this cohort, with natural tooth loss affecting food choice, quality of life and general health ${ }^{3}$. Currently, there is a lack of understanding of the factors which influence partially dentate older patients' treatment choices, particularly those for replacing missing teeth.

In many countries, partially dentate older patients are currently provided with RPDs as conventional treatment to replace missing teeth. Implant retained prostheses are an alternative approach to help manage tooth loss, but they are currently very expensive ${ }^{4}$. Less complex, functionally orientated treatment solutions are very applicable to this population including the SDA concept which aims to provide patients with a functional dentition of 10 occluding pairs of teeth or contacts without the need for a RPD. By preserving mainly anterior teeth the SDA concept can offer patients an aesthetic result which they can easily maintain ${ }^{5}$. From a public health viewpoint, functionally oriented tooth replacement should be very attractive as recent studies have demonstrated its ability to 
provide an acceptable level of oral function in a more cost-effective manner than conventional alternatives ${ }^{6,7}$.

Decisions about allocating resources between different tooth replacement strategies require evaluation to ensure the optimum health gain from any given budget. An important input into the decision making process is the value patients place on the services being considered $^{8}$. One approach to revealing an individual's strength of preference is to determine a monetary valuation through the individual's expression of their WPT for the intervention. WPT is the most commonly accepted monetary valuation technique ${ }^{9}$, where the respondent is presented with a hypothetical scenario in which a health care intervention or health state is to be valued and asked the maximum they would be willing to pay for the intervention or to improve their health state ${ }^{10,11}$. WTP is a form of contingency valuation (CV) that assigns monetary values to outcomes of health care in order to determine the net benefit. A relatively small number of oral healthcare investigations have utilised WTP methodology including Dixon and Shackley ${ }^{12}$ who estimated the benefits of community water fluoridation; and Cunningham and $\mathrm{Hunt}^{13}$ who investigated the relationship between utility values and WTP in patients undergoing orthognathic treatment. More recently Matthews investigated WTP for a novel oral topical anaesthetic using the payment card method $^{14}$, Vernazza investigated patient preferences for treatment of non vital teeth ${ }^{15}$ and Srivastrava conducted a web-based survey to establish the WTP of individuals with natural teeth for mandibular two-implant overdentures ${ }^{16}$. Whilst the application of WPT in capturing patient preferences for oral health interventions has been established in previous studies valuation of preferences for RPDs and functionally orientated tooth replacement has not been undertaken.

The primary aim of this study was to elicit WTP values from partially dentate elders' for two different tooth replacement strategies: RPDs and, functionally orientated treatment according to the principles of the SDA. The secondary aim was to measure the same patient groups' WTP for dental implant treatment. 


\section{Methodology}

Partially dentate patients aged 65 years and older were recruited from two centres: Cork University Dental Hospital (CUDH) and St Finbarr's Geriatric Day Hospital (SFDH) in Cork, Ireland. All of the patients included in the study had been provided with oral rehabilitation 24 months previously as part of a previous Randomised Controlled Clinical Trial comparing two tooth replacement strategies (RPDs and SDA) ${ }^{6,7,17}$. Patients were included in the original study if they had a minimum of 6 remaining natural teeth in one arch, no systemic medical conditions preventing routine dental treatment, no evidence of dementia, were able to have dental treatment in a dental chair and could communicate in English. Patients were randomly allocated to one of two treatment groups using a random number generator stratified for age and gender. Prior to prosthodontic rehabilitation all patients received routine dental care as required to render them dentally fit. Full ethical approval was provided by the Cork University Teaching Hospitals Ethical Approval Committee (ECM 5 (9) 05/02/08). Patients assigned to Group 1 (Conventional treatment) had all missing natural teeth replaced using a RPD. Those assigned to Group 2 (Functionally orientated treatment) were restored to 10 occluding tooth contacts using fixed adhesive bridgework according to the principles of the SDA.

An open-ended CV method of questioning, using the payment card method, was used to elucidate from 55 patients their maximum WTP for treatment to replace missing teeth in a number of hypothetical scenarios, coupled to different costs (Figure 1). In order to maximize the reliability of CV estimates the following checklist was used: pretesting the CV questionnaire on a focus group; face-to-face interviews; evaluation conducted by a blinded research assistant with no involvement in the previous RCT; breaking down WTP by a variety of respondent characteristics such as patient age, gender, social class (which was classified by data from longest held occupation), income levels (per year) and living circumstances and reminding respondents of their actual budget constraint when considering their WTP. The patients were divided into two groups according to their previous treatment allocation. Information was presented to all participants on each tooth replacement option including realistic costings for each treatment as CUDH is fee paying facility with information on treatment costs routinely provided to all patients $(\mathrm{RPD}=€ 600, \mathrm{SDA} € 450$ and implant 
provision $€ 2000)^{7}$. Respondents were asked to choose the one value which represented their maximum WTP values for each theoretical intervention.

The data gathered was analysed using PASW Statistics 18 software (formerly SPSS; IBM Company, Tokyo, Japan). Mann-Whitney $U$ tests and chai square tests were used to examine differences of demographic characteristics between the two treatment groups. A Mann-Whitney $U$ Test was used to compare differences in WTP values between the two treatment groups. To investigate predictive factors for WTP, multiple linear regression analyses were conducted. Independent variables were set as follows; age (continuous), gender (Female or Male), living circumstance (Alone, With Partner or Family), social class (Manual or Non-manual), current income level (<€10000, €10000-€20000, €20000-€30000, $€ 30000-€ 40000, € 40000-€ 50000,>€ 50000)$ and treatment group (SDA or RPD). A power calculation estimated a total sample size of 53 by $\mathrm{G}^{*}$ power when the defined effect size was 0.3 (large), $\alpha$ error probability was 0.05 , Power $=1-\beta$ error probability was 0.80 , and number of predictors was six in a multiple linear regression. $P$-values less than 0.05 were considered to be statistically significant.

\section{Results}

The demographic characteristics of the two treatment groups (SDA Group: $n=28$, RPD Group: $n=27$ ) were closed matched in terms of age distribution, gender, social class, living circumstances, highest and current income levels (Table 1). Highest income level and current income level are highly correlated (Spearman's rank-order correlation; $\rho=0.872$, $p<0.001)$.

Figure 2 illustrates the distribution of WTP values for RPDs, with the majority of patients in both treatment groups recording values lower than the actual treatment cost (€600). The median WTP for RPDs recorded by those patients who received this treatment was $€ 550$, which was significantly higher than those patients in the SDA Group ( $p=0.003$ ) (Table 2). Conversely, the majority of patients were willing to pay in excess of the market value for SDA treatment (€450) (Figure 3 ). For those patients previously treated with RPDs, their 
median WTP for SDA treatment was $€ 650$, which was significantly higher than that of SDA Group ( $p<0.001)$ (Table 2).

Regarding dental implant treatment, none of patients indicated that were willing to pay in excess of the stated treatment cost $(€ 2000)$ (Figure 4). The median WTP for dental implant treatment for both treatment groups was $€ 1000$ which represented $50 \%$ of the stated market value (Table 2).

Multiple linear regression modelling, indicated that current income level and treatment allocation significantly correlated to WTP for both RPD and SDA groups (Table 3 and Table 4). However, stated WTP for dental implant treatment was only significantly correlated with current income level (Table 5).

\section{Discussion}

The approach of this paper was to elucidate the opinions expressed by partially dentate patients about their preferences for tooth replacement strategies by simulating a hypothetical market through an open-ended CV method of questioning. The CV method of willingness to pay has the advantage over the more traditional economic evaluation methods, such as cost effectiveness or cost benefit, in that the benefit of the intervention can be compared directly with costs because they are both in monetary units. The CV method of WTP is particularly appropriate in this study because of its ability to consider the treatment alternatives as commodities and the value as a public good ${ }^{18}$.

Each of the patients within the study had received oral rehabilitation using conventional removable prostheses or according to a functionally orientated approach as part of a RCT. However, despite previous treatment allocation, both groups of patients indicated a very strong WTP for simpler, functionally orientated care using adhesive fixed prostheses (SDA). Those patients who had previously received functionally orientated care indicated a median WTP value which was $€ 100$ in excess of the stated treatment cost. In comparison, patients who had previously received RPDs indicated a significantly higher median WTP value for functionally orientated care which was $€ 200$ in excess of the stated treatment cost $(p<0.001)$. Conversely, neither group indicated a median WTP value which met the stated 
treatment cost for removable partial dentures. Previous studies have illustrated patients' dislike for removable prostheses which is expressed as a high degree of non-compliance with wearing RPDs, particularly those that replace solely posterior teeth ${ }^{19}$. These results also correlate with the increased maintenance burden RPDs place on patients. Previous results from this same patient group illustrate that those treated with RPDs had significantly more follow-up appointments than those treated according to the SDA concept ${ }^{7}$. Previous studies which have compared similar tooth replacement interventions have illustrated that levels of disease would be expected to be higher amongst those patients provided with RPDs which will necessitate further treatment. In addition, data on quality of life scores (OHIP-14), also collected as part of the RCT, illustrate that treatment based on the SDA concept achieved significantly better results than that based on RPDs 12 months after treatment intervention ${ }^{17}$. It would appear that these trends have been replicated and expressed via maximum WTP values.

As with other studies, a number of factors were seen to influence WTP values within this patient group. Regression modelling indicated that current income level and treatment allocation significantly correlated to WTP values for both RPD and SDA groups. However, stated WTP for dental implant treatment was only significantly correlated with current income levels. Previous studies have demonstrated that socio-economic class is predictive of WTP value ${ }^{20}$ but that was not the case in this patient group. Socio-economic class was determined by longest held occupation in this study and may not have provided accurate enough data to differentiate between groups. Influence of the level of income or the ability to pay on WTP seems to be a controversial topic in the current literature. Some researchers detected a positive association ${ }^{12,21}$, as in this study, whilst others found no influence ${ }^{13,20}$. It is somewhat surprising that gender did not influence WTP values recorded in this study as women tend to place a higher value on oral health and consume more oral health services.

Amongst the participants in this study, few displayed a strong WTP for dental implant treatment. Despite very conservative stated treatment costs for implant care $(€ 2000)$ both treatment groups indicated a median WTP value of only $€ 1000(p=0.511)$. This contrasts with previous WTP studies which indicate strong patient preferences for dental implants to replace missing teeth over treatment alternatives in Italy and Saudi Arabia ${ }^{21,22}$. However, the results mirror those found previously in Hong Kong where partially dentate patients 
recorded maximum WPT values of around half of the market price for implants to replace a missing tooth ${ }^{20}$. In this study neither treatment group had experience of dental implants but had received one of the other treatment interventions which may have influenced their decision. However, the WTP values may also have been a manifestation of patients' anxiety regarding dental implants, particularly the invasive surgical phase. This has been demonstrated previously in studies of older edentate patients in the United Kingdom offered implant retained overdentures where significant refusal rates were reported despite the removal of financial constraints ${ }^{29}$.

Whilst this study has generated interesting results a number of limitations must be acknowledged. Whilst 89 patients were eligible to participate in the study, 34 declined (38.2\%) despite a number of invitations from the research team. A larger sample size may have produced more robust data but no systematic differences were observed between the responders and non-responders. One limitation of the methodology utilised is the uncertainty of the participants' level of information pre-existing before their indication of treatment preference and valuation of WTP. It has been pointed out that the responses to utility measurement instruments depend on the accuracy, completeness, and clarity of the information provided ${ }^{15}$. These factors were not measured in this study and it was assumed that all participants fully understood the information provided. It must also be acknowledged that the participants level of income or ability to pay may have potentially influenced their stated WTP. In terms of information, participants were provided with realistic prices for the treatment alternatives in this study. This may have influenced maximum WTP values by acting as an anchoring effect on price judgements. However this was unavoidable due to the pricing policy of the study setting where patients routinely contribute financially to their dental care at the market rate. Whilst treatment costs were borne by a research grant in this study, price lists are routinely displayed in waiting rooms and provided with appointment letters from CUDH. Further work is required in this area to determine if these WTP trends are unique to this patient group or demonstrate wider opinions among partially dentate older patients. Comparisons should be made between patients of different generations, across countries and those attending prior to tooth replacement treatment. However, the use of tools such as WTP can be a method of better 
planning health services provision for older patients and making oral care truly patient centred.

\section{Conclusion}

Amongst this study population, WTP values were strongly influenced by previous treatment experience and current income levels. Both patient groups indicated a very strong WTP for simpler, functionally orientated care according to the principles of the SDA. Currently this treatment approach is not part of conventional patient care in many countries. Significant changes are required to ensure that dental care is truly patient centred including remuneration systems which often promote complex surgical and restorative treatments over minimally invasive approaches.

\section{Acknowledgement}

This study was supported by a grant from the Health Research Board of Ireland. (HRB/2008/220). The authors report no other conflicts of interest.

\section{References}

1. McKenna G, Allen PF, Schimmel M, Muller F. Who's picking up the bill? Gerodontology 2015; 32: 161-2.

2. Meija G, Jamieson LM, Ha D, Spencer J. Greater inequalities in dental treatment than in disease experience. Journal of Dental Research 2014; 93: 966-71.

3. Petersen PE, Kandelman D, Arpin S, Ogawa H. Global oral health of older people - a call for public health action. Community Dental Health 2010; 27: 257-67.

4. MacEntee MI, Walton JN. The economics of complete dentures and implant-related services: a framework for analysis and preliminary outcomes. Journal of Prosthetic Dentistry 1998; 79: 24-30. 
5. Kayser AF. Shortened dental arch: a therapeutic concept in reduced dentitions and certain high-risk groups. International Journal of Periodontics and Restorative Dentistry 1989; 9: 426-49.

6. McKenna G, Allen PF, Woods N, O'Mahony D, DaMata C, Cronin M et al. A preliminary report on the cost-effectiveness of tooth replacement strategies for partially dentate elders. Gerodontology 2013; 30: 207-13.

7. McKenna G, Allen PF, Woods N, O'Mahony D, Cronin M, DaMata C et al. Costeffectiveness of tooth replacement strategies for partially dentate elderly: a randomised controlled clinical trial. Community Dentistry and Oral Epidemiology 2014; 42: 366-74.

8. Donaldson C, Bate A. Resource management: The finite and beyond. The Health Service Journal 2006; 116: 20-21.

9. Vernazza C R, Wildman JR, Steele JG, Whitworth JM, Walls AWG, Perry R et al. Factors affecting patient valuations of caries prevention: Using and validating the willingness to pay method. Journal of Dentistry 2015; 43: 981-88.

10. Matthews DC, Gafni A, Birch S. Preference based measurements in dentistry: a review of the literature and recommendations for research. Community Dental Health 1999; 16: 5-11.

11. Birch S, Ismail Al. Patient preferences and the measurement of utilities in the evaluation of dental technologies. Journal of Dental Research 2002; 81: 446-50.

12. Dixon S, Shackley P. Estimating the benefits of community water fluoridation using a willingness-to-pay technique: results of a pilot study. Community Dentistry and Oral Epidemiology 1999; 27: 124-9.

13. Cunningham SJ, Hunt NP. Relationship between utility values and willingness-to-pay in patients undergoing orthognathic treatment. Community Dental Health 2000; 17: 92-6.

14. Matthews D, Rocchi A, Gafni A. Putting your money where your mouth is: willingness to pay for dental gel. Pharmoeconomics 2002; 20: 245-55.

15. Vernazza CR, Steele JG, Whitworth JM, Wildman JR, Donaldson C. Factors affecting direction and strength of patient preferences for treatment of molar teeth with nonvital pulps. International Endodontic Journal 2015; 48: 1137-46. 
16. Srivastava A, Feine JS, Esfandiari S. Are people who still have their natural teeth willing to pay for mandibular two-implant overdentures? Journal of Investigative and Clinical Dentistry 2014; 5: 117-24.

17. McKenna G, Allen PF, O'Mahony D, Cronin M, DaMata C, Woods N. The impact of rehabilitation using removable partial dentures and functionally orientated treatment on oral health-related quality of life: a randomised controlled clinical trial. Journal of Dentistry 2004; 43: 66-71.

18. Martin-Fernandez J, del Cura-Gonzalez IM, Rodriguez-Martinez G, Ariza-Cardiel G, Zamora J, Gomez-Gascon T et al. Economic valuation of health care services in public health systems: a study about Willingness to Pay (WTP) for nursing consultations. PLoS One 2013; 8: e62840

19. Jepson NJ, Thomason JM, Steele JG. The influence of denture design on patient acceptance of partial dentures. British Dental Journal 1995; 1995: 296-300.

20. Leung KCM, McGrath C. Willingness to pay for implant therapy: a study of patient preference. Clinical Oral Implants Research 2010; 21: 789-93.

21. Augusti D, Augusti G, Re D. Prosthetics restoration in the single-tooth gap: patient preferences and analysis of the WTP index. Clinical Oral Implants Research 2014; 25: 1257-64.

22. Al Garni B, Pani SC, Almaaz A, Al Qeshtani E, Abu-Ahimed H, Al Sharif K. Factors affecting the willingness to pay for implants: a study of patients in Riyadh, Saudi Arabia. Dental Research Journal 2012; 9: 719-24.

23. Ellis JS, Levine A, Bedos C, Mojon P, Rosberger Z, Feine J et al. Refusal of implant supported mandibular overdentures by elderly patients. Gerodontology 2011; 28: 62-8. 


\begin{tabular}{|c|c|c|c|}
\hline Treatment & SDA & RPD & $\begin{array}{c}\text { Dental } \\
\text { Implant }\end{array}$ \\
\hline Average cost (€) & 450 & 600 & 2000 \\
\hline \multirow{3}{*}{ WTP (€) } & 300 & 300 & 500 \\
& 350 & 350 & 1000 \\
& 400 & 400 & 1500 \\
& 450 & 450 & 2000 \\
& 500 & 500 & 2500 \\
& 550 & 550 & 3000 \\
& 600 & 600 & 3500 \\
& 650 & 650 & 4000 \\
& 700 & 700 & \\
& 750 & 750 & \\
\hline
\end{tabular}

Figure 1: Payment card

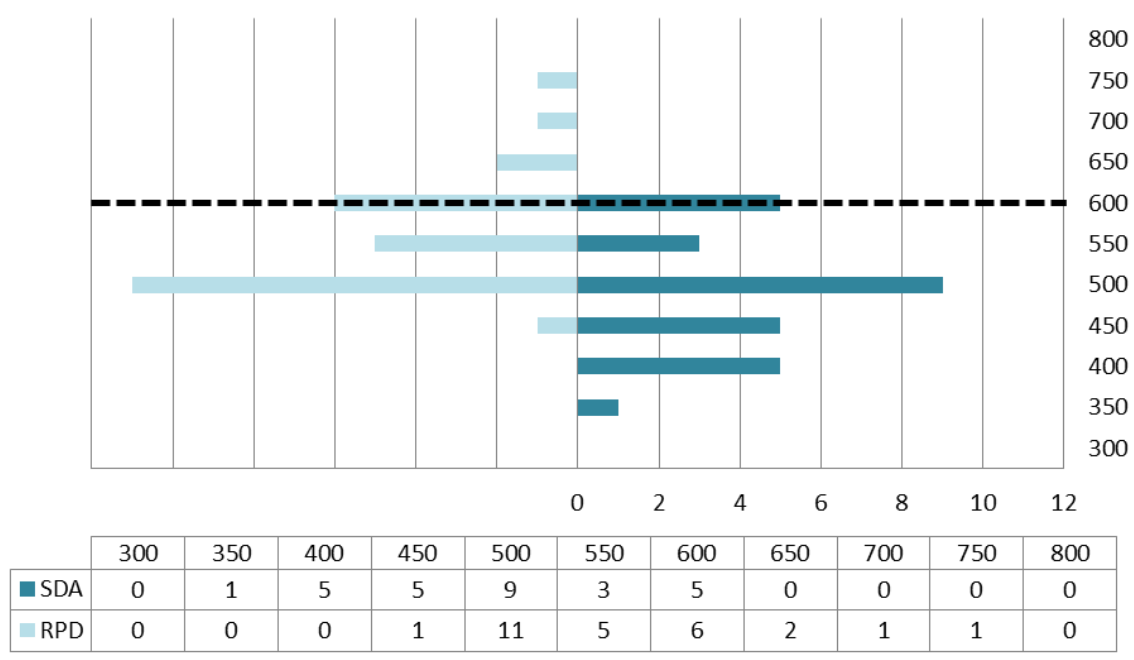

Figure 2: Distribution of WTP values for RPD Treatment

(Broken line indicates stated treatment cost for RPD Treatment) 


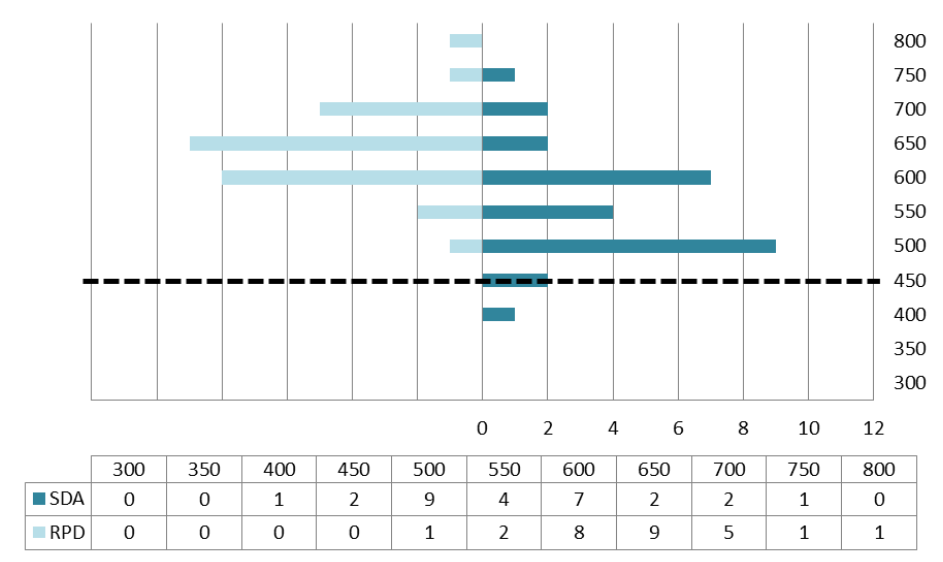

Figure 3: Distribution of WTP values for SDA Treatment

(Broken line indicates the stated treatment cost for SDA Treatment)

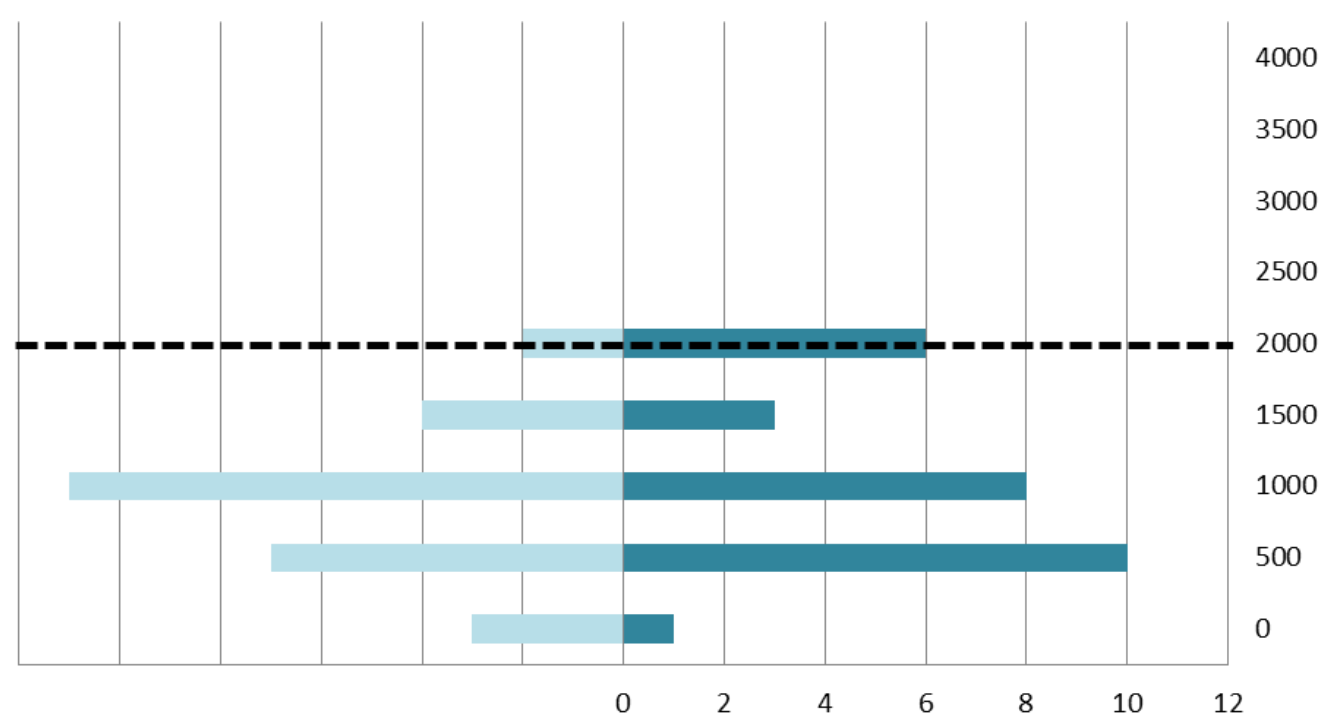

\begin{tabular}{|c|c|c|c|c|c|c|c|c|c|}
\cline { 2 - 10 } \multicolumn{1}{c|}{} & 0 & 500 & 1000 & 1500 & 2000 & 2500 & 3000 & 3500 & 4000 \\
\hline$\square$ SDA & 1 & 10 & 8 & 3 & 6 & 0 & 0 & 0 & 0 \\
\hline RPD & 3 & 7 & 11 & 4 & 2 & 0 & 0 & 0 & 0 \\
\hline
\end{tabular}

Figure 4: Distribution of WTP values for Dental Implant Treatment (Broken line indicates the stated treatment cost for Dental Implant Treatment) 
Table 1: Patient demographics

\begin{tabular}{|c|c|c|c|}
\hline & $\begin{array}{l}\text { SDA Group } \\
(n=28)\end{array}$ & $\begin{array}{l}\text { RPD Group } \\
(\mathrm{n}=27)\end{array}$ & p-value \\
\hline Age (Median (IQR)) & $\begin{array}{c}71.50 \\
(70.00-74.75)\end{array}$ & $\begin{array}{c}73.00 \\
(72.00-75.00)\end{array}$ & $\begin{array}{c}0.279 \\
\text { (MWU test) }\end{array}$ \\
\hline $\begin{array}{l}\text { Gender } \\
\text { Female } \\
\text { Male }\end{array}$ & $\begin{array}{l}15(54 \%) \\
13(46 \%)\end{array}$ & $\begin{array}{l}16(59 \%) \\
11(41 \%)\end{array}$ & $\begin{array}{c}0.671 \\
\left(\chi^{2} \text { test }\right)\end{array}$ \\
\hline $\begin{array}{l}\text { Social Class* } \\
\text { Manual } \\
\text { Non-Manual }\end{array}$ & $\begin{array}{l}14(50 \%) \\
14(50 \%)\end{array}$ & $\begin{array}{l}14(52 \%) \\
13(48 \%)\end{array}$ & $\begin{array}{c}0.891 \\
\left(\chi^{2} \text { test }\right)\end{array}$ \\
\hline $\begin{array}{l}\text { Living Circumstance } \\
\text { Alone } \\
\text { With Partner or Family }\end{array}$ & $\begin{array}{c}6(21 \%) \\
22(79 \%)\end{array}$ & $\begin{array}{c}4(15 \%) \\
23(85 \%)\end{array}$ & $\begin{array}{c}0.525 \\
\left(\chi^{2} \text { test }\right)\end{array}$ \\
\hline $\begin{array}{c}\text { Highest Income Level }(€) \\
20,000-30,000 \\
30,000-40,000 \\
40,000-50,000 \\
50,000-60,000 \\
60,000-70,000 \\
>70,000\end{array}$ & $\begin{array}{c}11(39 \%) \\
3(11 \%) \\
4(14 \%) \\
5(18 \%) \\
0(0 \%) \\
5(18 \%)\end{array}$ & $\begin{array}{c}9(33 \%) \\
4(15 \%) \\
3(11 \%) \\
5(19 \%) \\
1(4 \%) \\
5(18 \%)\end{array}$ & $\begin{array}{c}0.917 \\
\left(\chi^{2} \text { test }\right)\end{array}$ \\
\hline $\begin{array}{c}\text { Current Income Level }(€) \\
0-10,000 \\
10,000-20,000 \\
20,000-30,000 \\
30,000-40,000 \\
40,000-50,000 \\
>50,000\end{array}$ & $\begin{array}{l}3(11 \%) \\
5(18 \%) \\
8(29 \%) \\
6(21 \%) \\
4(14 \%) \\
2(7 \%)\end{array}$ & $\begin{array}{c}7(26 \%) \\
0(0 \%) \\
11(41 \%) \\
5(19 \%) \\
2(7 \%) \\
2(7 \%)\end{array}$ & $\begin{array}{c}0.167 \\
\left(\chi^{2} \text { test }\right)\end{array}$ \\
\hline
\end{tabular}


Table 2: WTP for Tooth Replacement options ( ${ }^{*} p$-values Statistically Significant, MannWhitney U Test)

\begin{tabular}{|c|c|c|c|c|}
\hline & $\begin{array}{c}\text { SDA Group } \\
(\mathbf{n = 2 8})\end{array}$ & $\begin{array}{c}\text { RPD Group } \\
(\mathrm{n}=\mathbf{2 7})\end{array}$ & p-value & Actual treatment cost (€) \\
\hline $\begin{array}{c}\text { Median WTP for RPD } \\
\text { Treatment }(\boldsymbol{\epsilon})\end{array}$ & $\begin{array}{c}500 \\
\text { (IQR: } 450-550)\end{array}$ & $\begin{array}{c}550 \\
\text { (IQR: } 500-650)\end{array}$ & $0.003^{*}$ & 600 \\
\hline $\begin{array}{c}\text { Median WTP for SDA } \\
\text { Treatment (€) }\end{array}$ & $\begin{array}{c}550 \\
\text { (IQR: } 500-600)\end{array}$ & $\begin{array}{c}650 \\
\text { (IQR: } 600-650)\end{array}$ & $<0.001^{*}$ & 450 \\
\hline $\begin{array}{c}\text { Median WTP for Dental } \\
\text { Implant Treatment (€) }\end{array}$ & $\begin{array}{c}1000 \\
\text { (IQR: } 500-1000)\end{array}$ & $\begin{array}{c}1000 \\
\text { (IQR: } 500-1000)\end{array}$ & 0.511 & 2000 \\
\hline
\end{tabular}

Table 3: Multiple regression model of WTP for RPD Treatment

\begin{tabular}{|c|c|c|c|c|c|}
\hline Variables & correlation & B & $\beta$ & p-value & $95 \%$ Cl for B \\
\hline Treatment Allocation & 0.425 & 75.6 & 0.49 & $<0.001$ & $41.2-109.9$ \\
\hline Current Income Level & 0.399 & 24.5 & 0.45 & 0.002 & $9.8-39.2$ \\
\hline Age & -0.217 & -5.9 & -0.22 & 0.059 & $-12.1-0.2$ \\
\hline Living Circumstance & 0.203 & 27.7 & 0.14 & 0.216 & $-16.8-72.2$ \\
\hline Gender & 0.015 & -16.3 & -0.10 & 0.361 & $-51.9-19.3$ \\
\hline Social Class & -0.285 & 6.5 & 0.04 & 0.767 & $-37.4-50.4$ \\
\hline
\end{tabular}

$R^{2}=0.449(p<0.001), F_{(6,48)}=6.521(p<0.001)$ 
Table 4: Multiple regression model of WTP for SDA Treatment

\begin{tabular}{|c|c|c|c|c|c|}
\hline Variables & correlation & B & $\beta$ & p-value & $95 \%$ Cl for B \\
\hline Treatment Allocation & 0.049 & 92.3 & 0.55 & $<0.001$ & $57.1-127.5$ \\
\hline Current Income Level & 0.440 & 31.8 & 0.55 & $<0.001$ & $16.7-46.9$ \\
\hline Social Class & -0.207 & 17.2 & 0.10 & 0.445 & $-27.8-62.2$ \\
\hline Living Circumstance & -0.005 & -14.8 & -0.07 & 0.518 & $-60.3-30.8$ \\
\hline Age & -0.012 & -0.8 & -0.03 & 0.800 & $-7.1-5.5$ \\
\hline Gender & 0.120 & 2.2 & -0.01 & 0.906 & $-34.3-38.6$ \\
\hline
\end{tabular}

$R^{2}=0.495(p<0.001), F_{(6,48)}=7.827(p<0.001)$

Table 5: Multiple regression model of WTP for Dental Implant Treatment

\begin{tabular}{|c|c|c|c|c|c|}
\hline Variables & correlation & B & $\beta$ & p-value & $95 \% \mathrm{Cl}$ for $\mathrm{B}$ \\
\hline Current Income Level & 0.710 & 274.3 & 0.69 & $<0.001$ & $172.4-376.7$ \\
\hline Treatment Allocation & -0.128 & -70.3 & 0.06 & 0.554 & $-307.6-166.9$ \\
\hline Gender & 0.252 & 51.6 & 0.05 & 0.675 & $-194.4-297.5$ \\
\hline Age & -0.105 & 7.6 & 0.04 & 0.722 & $-35.0-50.1$ \\
\hline Living Circumstance & 0.026 & -17.7 & -0.01 & 0.908 & $-325.2-289.7$ \\
\hline Social Class & -0.413 & -14.9 & -0.01 & 0.922 & $-318.3-288.5$ \\
\hline
\end{tabular}

$R^{2}=0.511(p<0.001), F_{(6,48)}=8.360(p<0.001)$ 